\title{
COTTON EVAPOTRANSPIRATION USING VERY HIGH SPATIAL RESOLUTION WV-2 SATELLITE DATA AND GROUND MEASUREMENTS FOR PRECISION AGRICULTURE
}

\author{
NICHOLAS DERCAS ${ }^{1}$, NICOS V. SPYROPOULOS ${ }^{2}$, NICOLAS R. DALEZIOS ${ }^{1}$, \\ EMMANOUIL PSOMIADIS ${ }^{1}$, ANGELIKI STEFOPOULOU ${ }^{1}$, GEORGIOS MANTONANAKIS ${ }^{1}$ \\ $\&$ NICHOLAS TSERLIKAKIS ${ }^{1}$ \\ ${ }^{1}$ Department of Natural Resources Management and Agricultural Engineering, \\ Agricultural University of Athens, Greece \\ ${ }^{2}$ SIGMA Geotechnologie, Germany
}

\begin{abstract}
In this paper, the preliminary results on Crop Coefficient $(\mathrm{Kc})$ estimation are presented with the view to assess the crop evapotranspiration in specific cotton fields during the growing season of 2015 and 2016 in Thessaly, Greece. Several World View 2 (WV-2) satellite images were used. The so-called ETcsat (Evapotranspiration from satellite data) produced by using the Reference Evapotranspiration (ETo) from Food and Agriculture Organization of the United Nations (FAO) based on meteorological data and Kc extracted from Normalized Difference Vegetation Index (NDVI) utilizing the Red and Near Infra-Red (NIR) bands. The values of ETcsat are close to Crop Evapotranspiration (ETc) during the cultivation period of cotton and the estimation of ETc is successful. Kc and RedNDVI relationship is based on WV-2 images and water balance in the field scale. The methodology has proved to be very useful for the implementation and verification of any Integrated Management Programme System for optimal agricultural production.

Keywords: satellites, NDVI, FAO, ETc, Kc.
\end{abstract}

\section{INTRODUCTION}

Agricultural production strongly depends on water availability. Similarly, climate variability has a significant impact on agricultural production at local, regional, as well as global scales. Indeed, crop yields are affected by variations in meteorological variables, such as air temperature and precipitation. Several regions around the world, including the entire Mediterranean basin, are characterized as vulnerable areas affecting agriculture due to the combined effect of reduced precipitation and temperature increases in areas already facing water scarcity [1]. Agricultural production risks to become an issue in the Mediterranean region as mainly droughts and heat waves are likely to increase the incidence of crop failure. Irrigation has always been significant for crop production in most Mediterranean countries mainly due to high evapotranspiration rates and restricted rainfall inputs. The demand for irrigation water is projected to rise in a warmer climate, increasing the competition between agriculture and urban, as well as industrial, users of water [2]. More water is expected to be required per unit area under drier conditions, and peak irrigation demands are also predicted to rise due to more severe heat waves. Precision agriculture, which is considered in this paper, is a rather recent approach to address the issues of water needs for effective crop water and fertilizer monitoring in vulnerable agroecosystems [3].

For the assessment of water needs for agriculture, the estimation of Crop Evapotranspiration $\left(\mathrm{ET}_{\mathrm{c}}\right)$ is required. $\mathrm{Kc}$ is a vegetation coefficient that is closely related to the phenological cycle of vegetation and is related to the NDVI values. The Kc is also closely related to vegetation canopy and the degree of vegetation vigour and it is 
also related to ET. Several research works have shown [4], [5] that it is possible to estimate the water irrigation needs of a crop by calculating the $\mathrm{ET}_{\mathrm{c}}$ from satellite data mainly using the Kc coefficient, which is derived by a vegetation index. The full $\mathrm{ET}_{\mathrm{c}}$ estimation equation is based on eqn (1).

$$
\mathrm{ET}_{\mathrm{c}}=(\mathrm{KsKcb}+\mathrm{Ke}) \mathrm{ETo},
$$

where the Basal Crop Coefficient $(\mathrm{Kcb})$ is defined as the ratio of the crop evapotranspiration over the reference evapotranspiration (ETc/ETo) when the soil surface is dry but transpiration is occurring at a potential rate, i.e., water is not limiting transpiration. Therefore, 'KcbETo' represents primarily the transpiration component of ETc. Ke is the soil water evaporation coefficient; it describes the evaporation component from the soil surface. The water stress coefficient (Ks) describes the effect of water stress on crop conditions. For soil water limiting conditions, $\mathrm{Ks}_{\mathbf{s}}<1$. Where there is no soil water stress, then $\mathrm{Ks}_{\mathrm{s}}=1$.

$$
\mathrm{Kcb}=1.5625 * \mathrm{NDVI}-0.1
$$

Kcb values were between 0.15 and 1.15 using a set of Landsat7 satellite images [6]. An approximation to a single crop coefficient $\mathrm{Kc}$ is the following:

$$
\mathrm{Kc}=1.25 * \mathrm{NDVI}+0.20
$$

for the initial, development and mid-season, and

$$
\mathrm{Kc}=1.5625 * \text { NDVI }-0.05
$$

for the late season [6]. Kc is a spectral crop coefficient that is taking values between 0.15 and 1.20 .

In addition, the following equations have been found in the literature [7]:

$$
\begin{aligned}
& \mathrm{Kc}=1.15 * \mathrm{NDVI}+0.17 \\
& \mathrm{Kc}=1.25 * \mathrm{NDVI}+0.10
\end{aligned}
$$

The present work describes the calculation of Kc from RedNDVI time series and is compared to Kc generated by FAO approach. Then the ETcsat is produced by using the reference ETo from FAO, based on meteorological data and $\mathrm{Kc}$ extracted by NDVI utilizing the Red, the first and the second NIR bands of WV-2, respectively. Fig. 1 delineates the above methodology.

\section{MATERIALS AND METHODS}

Six WV-2 scenes were atmospherically, radiometrically and geometrically corrected [8], [9], over cotton farm of the Greek FATIMA site. The Kc was continuously generated from vegetation indices as new satellite data were added in the time series data set. Two agricultural fields (1.8 ha and 1.0 ha respectively) were used in summer 2015 (May to September) and 2016 (April to September) as experimental test sites for the project located in Larisa, Central Greece. In 2015 cotton emerged on the $26^{\text {th }}$ May (it was necessary to sow twice due to hail storm). In 2016 cotton emerged on the $18^{\text {th }}$ April. They were divided in blocks, with each block receiving various fertilization treatments: conventional fertilization (according to the farmers' practice), variable rate technology fertilization (VRT) and control (only basic fertilization). Soil moisture was monitored with a ground sensors 
network. Six (6) WV-2 $2 \mathrm{~m}$ multi and $0.5 \mathrm{~m}$ pan - sharpened images processed during the growing seasons for the purpose of producing maps of canopy reflectance. The acquisition dates were May (17), June (13), July (29), Sep (2) 2015, July (8) and August (12) of 2016. The atmospheric correction was based on ATCOR3 (ATmospheric CORrection, version 3) model developed by German Aerospace Center (Deutsches Zentrum für Luft - und Raumfahrt - DLR) calibrating the data for Top of Atmosphere (TOA) and Ground reflectance. The geometric registration was based on two different approaches: geocoding using image-to- GCPs (Ground Control Points) and image-to-image as a master-to-slave approach [10]. The first WV-2 acquired on May 2015 was corrected by using 10 GCPs. All the following images were orthorectified on the first image using, image to image registration.

This is the first step of a series of comparisons, as FATIMA project is ongoing up to 2018 , in order to select the appropriate equation that fits to a specific area, crop type and sensor. More analytically, for two irrigated crop fields (cotton) in Thessaly (Central Continental Greece) soil moisture measurements (Ground) and WV-2 satellite (Sat) recordings are used to perform a new equation for Kc estimation. The following parameters were collected from satellite:

Spectral bands:

- RED

- NIR X 2 (due to WV-2 two infrared channels)

Vegetation Indices:

\section{- $\quad$ Red NDVI}

The Kc presented here is developed from the NDVI indices using and Red, NIR(1) and NIR(2) of WV-2 channels. This is tried for the first time with new bands, especially with a second NIR of WV-2, which is less influenced by atmosphere. The indices were applied onto $2 \mathrm{~m}$ multispectral data and on pan - sharpened $0.5 \mathrm{~m}$ data. Pan - sharpening is a digital synthesis, whereas the $2 \mathrm{~m}$ multispectral channels are merged with the $0.5 \mathrm{~m}$ panchromatic channel to generate another set of multispectral channels that preserve the spectral information, but in higher spatial feature space of $0.5 \mathrm{~m}$, thus enhancing the information integrity and clarity.

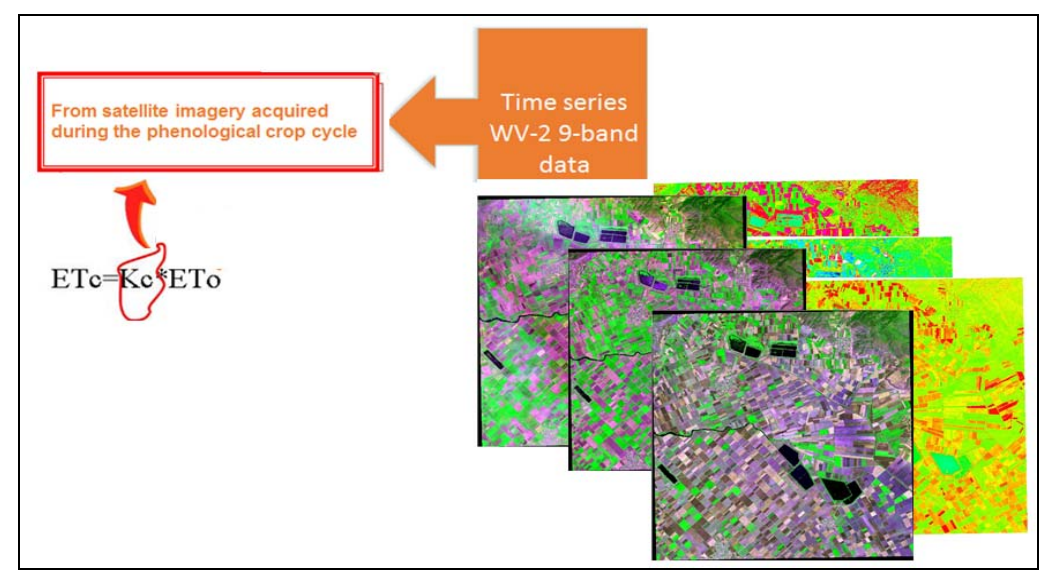

Figure 1: The role of $\mathrm{Kc}$ in the estimation of evapotranspiration. 
The Kc work included:

- Development of NDVI from WV-2 and comparison of the produced values (generation of different NDVIs using as much as possible the same spectral bands with similar wavelength range).

- Use the Kc of FAO for cotton.

- Monitoring of the soil moisture, establishment of the water balance in the field scale, and evaluation of the Kc during the various stages of the two cultivation periods.

The following data - table is the Kc, given by FAO [11].

\section{RESULTS}

All available Kc equations mentioned above are based on Landsat -5 and 7 missions. In order to adjust the Kc satellite values from WV-2 images it is necessary to build a new Kc equation that allows the estimation of crop water needs. In other words, to suitably select the $\mathrm{a}$ and $b$ coefficients in the linear system of $\mathrm{y}=a \mathrm{x}+b$, where $\mathrm{y}$ is the Kc from satellite and $\mathrm{x}$ is the satellite NDVI. The appropriate Kc equation describes the cotton Kc derived from WV-2 Red and NIR spectral bands and for this specific geographic area.

Table 1: Typical FAO Kc values for cotton.

\begin{tabular}{|l|l|l|l|l|l|l|l|l|}
\hline Plant & Kc1 & Kc2 & Kc3 & St1 & St2 & St3 & St4 & total \\
\hline Cotton & 0.35 & 1.15 & 0.70 & 30 & 50 & 60 & 55 & 195 \\
\hline
\end{tabular}

Table 2: Comparison of Kc sat and ETcsat built from WV-2 satellite with Kc and ETc by FAO for cotton farm of summer 2016.

\begin{tabular}{|l|l|l|l|l|}
\hline & \multicolumn{2}{|l|}{ Comparison of Kc } & \multicolumn{2}{l|}{ Comparison of ET $(\mathrm{mm})$} \\
\hline Date & Kc sat & Kc FAO & ETcsat & ETc \\
\hline 8 July & 1.02 & 1.15 & 5.1 & 5.8 \\
\hline 12 Aug & 1.07 & 1.15 & 4.9 & 5.3 \\
\hline
\end{tabular}

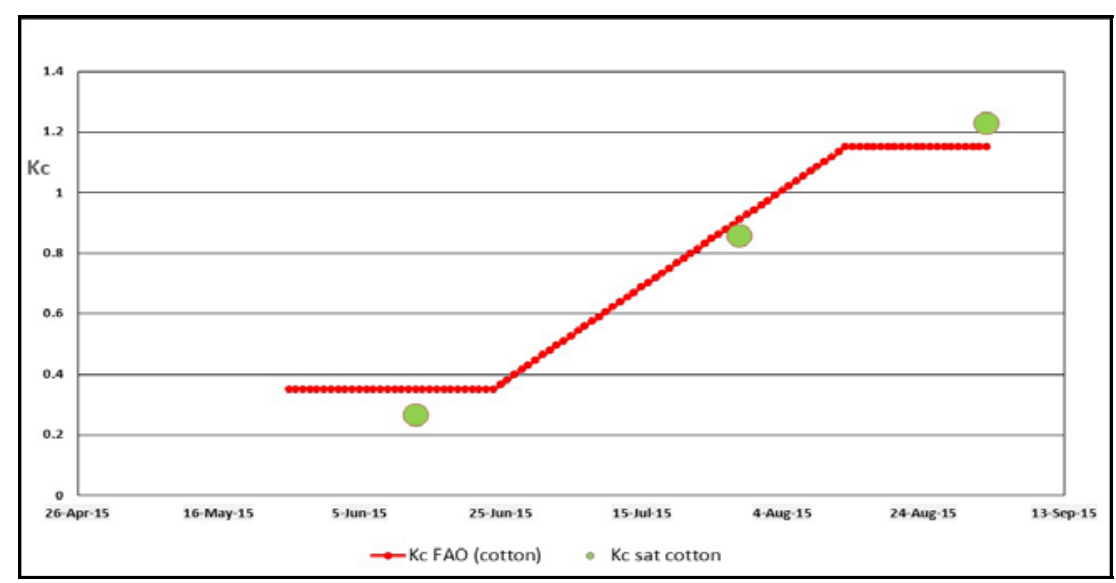

Figure 2: Comparison of Kc built from WV-2 satellite and FAO for cotton farm of summer 2015. 


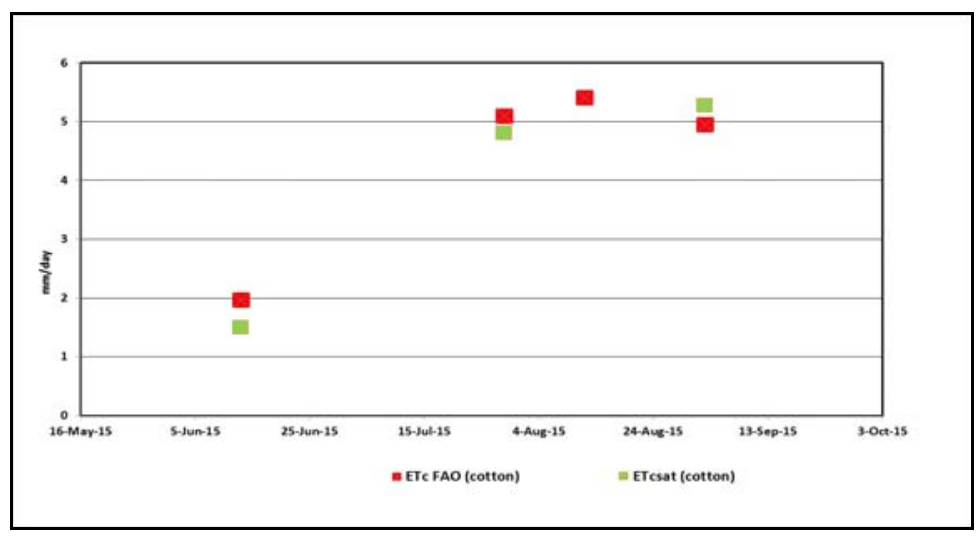

Figure 3: Comparison of ETcsat built from WV-2 satellite and ETc produced by FAO for cotton farm of summer 2015.

Figure 4:

The following regression eqn. (7) is obtained from soil moisture measurements, meteorological data, water balance calculation at the field scale and RedNDVI extracted from WV-2 data.

$$
\mathrm{Kc}=1.33(\operatorname{RedNDVI})+0.21\left(\mathrm{R}^{2}=0.92\right)
$$

It shall be noted that values obtained by eqn. (8) are very close to the Kc derived by FAO (Fig. 2 and Table 2).

\section{DISCUSSION}

Kc sat values (average values in the field scale) based on Red and NIR spectral bands of WV-2 data and Kc values from FAO for the same summer months of the years 2015 and 2016 are close to each other (Fig. 2 and Table 2). It is clear that for both periods the Kc coefficient was successfully estimated using the WV-2 satellite data. Of course, more earth observation data are needed to validate these results.

It is understood that this $\mathrm{Kc}$ estimation based on satellite data ( $\mathrm{Kc} \mathrm{sat})$, is a very dynamic one, and follows the exact conditions of the crop in the field according to its phenological cycle including the recording of any sudden event occurred within this crop. Overall, the Kc values from the WV-2 data are close to the Kc FAO values. Similarly, the ETcsat values for cotton crop during the summer of 2015 follow the curve of ETc from FAO (Fig. 3) (ETc obtained using Kc and ETo according to FAO-56 [11]. For the summer of 2016, the ETcsat is lower than ETc (Table 2), but the values obtained for July and August are close (ETcsat $\sim 5 \mathrm{~mm} /$ day and ETc $\sim 5.5 \mathrm{~mm} /$ day). Fig. 4 shows the Red NDVI of WV-2 for cotton fields during the summers of 2015 and 2016.

\section{CONCLUSIONS}

The results indicate that it is possible to estimate evapotranspiration via the Kc coefficient, which is derived by satellite data. However, $\mathrm{Kc}$ is dependent on the type of satellite data and cannot be applied in a generic way. Spatial and spectral resolutions are the key components of any sensor that is going to be used for Kc extraction. Sensors with different bandwidth of Red, Red Edge and NIR spectral bands create heterogeneous results. Additionally, the type and size of farm plays a very important role on the selection of satellite data and thus on the Kc equation to be used. For example, the small size farms or land fragmentation, which is mainly present in the Greek and Italian farms, require very 
high spatial resolution data instead of mid resolution data [12]. All these issues are expected to be overcome with the forthcoming constellations, such as Urthe Daily (2019), where their daily coverage and robust spatial resolution of $5 \mathrm{~m}$, highly - calibrated and similarity of Red, Red - edge and NIR channel wavelengths with current sensors of Landsat 8 and Sentinel 2A/2B will eliminate the trade - off between very high and mid resolution satellites, offering an unprecedented generation of series of pixels or series of knowledge over an agricultural plot.

Overall, the present work demonstrated that the development and implementation of an efficient site - specific management system in the case of precision agriculture for reducing irrigation is possible by combining field measurements and well-defined satellite data coverage intervals. Satellites have proved to be ideal due to their global repetitive coverage over an area of interest (every 2-3 days), spatial and spectral resolution. The comparison of satellite data and field measurements has shown that the utilization of WV-2 is definitely a useful tool for farm based stakeholders, allowing not only the extraction of crop area, but also the derivation of useful parameters, such as the Kc satellite and ETcsat that can be used in the estimation of crop water needs [3]. The latter can lead to the implementation and verification of any Integrated Management Program System for optimal agricultural production compliant with EU AGRO 2.1 and 2.2 standards for agricultural production. It is also expected that this research work will be amplified by Sentinel 2/A/B data and the results will be presented in the coming months.

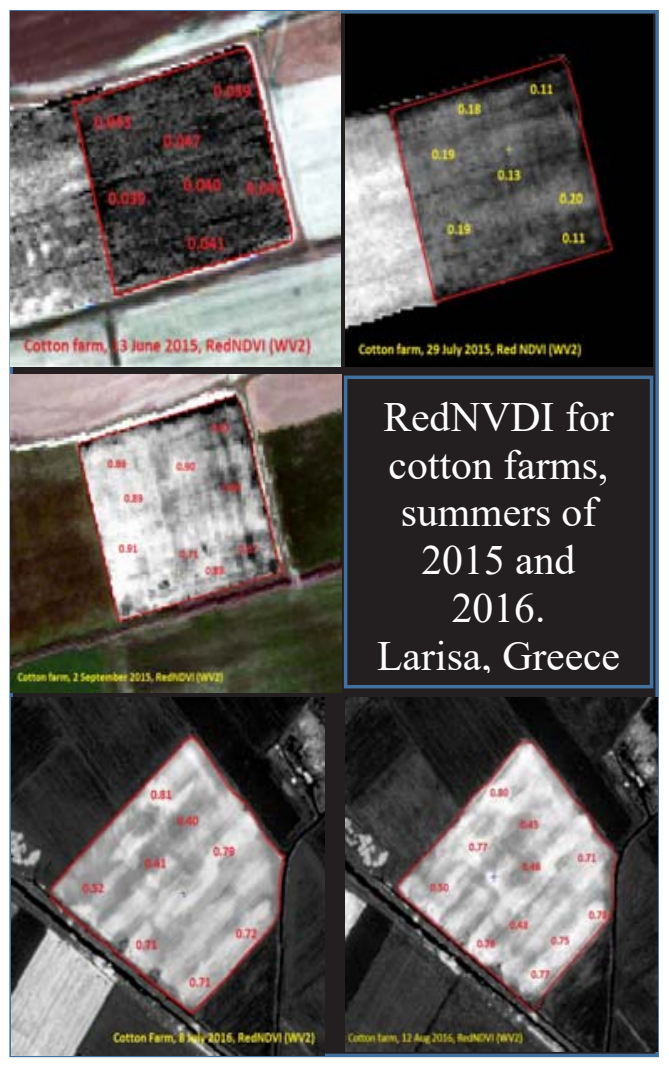

Figure 4: RedNDVI of WV-2 for cotton fields, summers of 2015 and 2016. 


\section{ACKNOWLEDGEMENT}

The work executed as a part of FATIMA, an EU funded project (Grant Agreement number: 633945 - FATIMA - H2020 - SFS - 2014 - 2015/H2020 - SFS - 2014 - 2). FATIMA stands for "Farming tools for external nutrient inputs and water management".

\section{REFERENCES}

[1] Dalezios, N.R., N. Dercas, N \& Eslamian, S., Water Scarcity Management: Part 2: Satellite-based Composite Drought Analysis, IJHST. (accepted, in press), 2016.

[2] Olesen, J.E. \& Bindi, M., Consequences of climate change for European agricultural productivity, land use and policy, European Journal of Agronomy, 16 pp. 239-262, 2002.

[3] Dalezios, R.N., Spyropoulos, N. \& Mplanta, A., Agrometeorological Remote Sensing of High Resolution for Decision Support in Precision Agriculture. Advances in Meteorology, Climatology and Atmospheric Physics, Springer Atmospheric Sciences, DOI 10.1007/978-3-642-29172-2_8, Springer-Verlag Berlin Heidelberg 2012.

[4] Guido D’Urso G. \& Vuolo F., FATIMA Project. Work Package 2.2; Activity 1: "Time Series of satellite data from multiple satellites in near real time" Project deliverable D 2.2.1. Methodology for dense high-resolution EO time series, gap filled. 2015.

[5] Gonzalez -Piqueras, J., Calera, A., Gilabert, M A., Cuesta, A., De la Cruz, F. T., Estimation of crop coefficients by means of optimized vegetation indices for corn La Mancha, Spain). SPIE Proceedings, 5232, pp. 110-118, 2004.

[6] Guido D'Urso, A. \& Calera, B. Operative approaches to determine crop water requirements from earth observation data: Methodologies and applications. Earth observation for vegetation monitoring and water management, AIP Conference, Eds G.D’Urso, M.A. Osann J. \& Moreno J., Naples, Italy, pp. 14-23, 2005.

[7] Dalezios,N.R., Mplanta, A. \& Domenikiotis, C., Remotely Sensed Cotton Evapotranspiration for irrigation Water Management in Vulnerable Agriculture of Central Greece, J of Information Technology Agriculture, 4, (1), pp. 1-14, 2011.

[8] Lanzl, F. \& Richter, R., A fast atmospheric correction algorithm for small swath angle satellite sensors. ICO topical meeting on atmospheric, volume, and surface scattering and propagation, Florence, Italy, August 1991.

[9] Updike, T. \& Comp, C., Radiometric use of WorldView-2 Imagery. Technical Note, DigitalGlobe, 1601 Dry Creek Drive Suite 260 Longmont, Colorado, USA, 80503, 2010.

[10] Spyropoulos, N., The benefits of high-resolution earth imagery in agriculture -The Ikonos system and its applications to agri-environment schemes. $1^{\text {st }}$ workshop on the management and monitoring of agri-environment schemes, Joint Research Center (JRC),Ispra, Italy, pp. 23-24, Nov. 1999.

[11] Allen, R.G., Pereira, L.S., Raes D \& Smith, M.,. Crop evapotranspiration: guidelines for computing crop water requirements. FAO Irrigation and Drainage Paper, 56, p. 300, Rome, 1998.

[12] Spyropoulos, N., Image segmentation, classification and feature extraction. XXII FIG international congress. ACSM-ASPRS conference and technology exhibition, Washington, D.C, April pp. 19-26, 2002. 